\title{
Does the nucleation of clay minerals control the rate of diagenesis in sandstones?
}

\author{
MARK WILKINSON \\ University of Edinburgh, Grant Institute, James Hutton Road, Edinburgh EH9 3FE, UK
}

(Received 15 November 2014; accepted 28 April 2015; Associate Editor: H. Stanjek)

\begin{abstract}
AB S TRACT: Nucleation is much more important for clay minerals than for other authigenic cements as clay crystals are very small, so that a very large number of clay crystals must be nucleated. The role of this difficult kinetic step in the diagenesis of sandstones has not been considered adequately as a ratedetermining process. The relationship between pore-fluid supersaturation and the rate of nucleation of a mineral is very different from the relationship between supersaturation and the rate of crystal enlargement; thus the two processes will act at very different rates. A diagenetic model that predicts claymineral formation but omits the nucleation stage may make unreliable predictions. This may account partially for the discrepancy between numerical simulations of $\mathrm{CO}_{2}$ injection that predict high degrees of reaction between the $\mathrm{CO}_{2}$ and the host rock, and the results of studies of natural analogues that have much lower degrees of reaction.
\end{abstract}

KEYwORDS: nucleation, clay mineral, diagenesis.

The rates of mineral reactions during weathering and diagenesis that have been determined experimentally can be several orders of magnitude greater than those determined using in situ studies of natural analogues (White \& Brantley, 2003; Blum \& Stillings, 1995). The rates of mineral reactions in sandstones have been used extensively in computer simulations of both natural diagenesis and of reactions induced by the injection of $\mathrm{CO}_{2}$ for storage or enhanced oil recovery. For example, Small (1993) used laboratory rates of illite growth to predict the complete illitization of sandstones in only $\sim 100,000$ years, whereas the reaction appears to be incomplete even after millions of years in deeply buried sandstones.

As the majority of rock-forming minerals are only sparsely soluble, the dissolution of one or more minerals must be accompanied by the precipitation of different minerals, given the relatively low water-rock ratios within a typical sandstone (e.g. Bjørlykke \&

E-mail: Mark.Wilkinson@ed.ac.uk DOI: 10.1180/claymin.2015.050.3.01
Aagaard, 1992); e.g. an 'unstable' mineral such as feldspar cannot dissolve unless a more stable clay mineral can precipitate from the released solutes. If the nucleation of a clay mineral is the slowest step of a reaction, then it will be rate determining. If each clay crystal could grow to a 'large' size once nucleation was achieved, then enlargement could continue without more nucleation. However, clay crystals rarely enlarge beyond a certain (very small) size, so once each crystal has reached its maximum size, then more nucleation must occur for precipitation to continue. The aim of this paper is to suggest that the discrepancy observed between the rates of laboratory simulations of diagenetic reactions and the rates of comparable reactions in situ may be due to the effects of nucleation, thus proposing that the rate of nucleation of clay minerals should be incorporated into all models of diagenesis (including the injection of $\mathrm{CO}_{2}$ for engineered storage). Note that due to the availability of precursor surfaces, homogeneous nucleation probably never occurs in diagenesis; see Mullin (2001) for a review of nucleation. The rates of diagenetic reactions in shales are not considered here. 


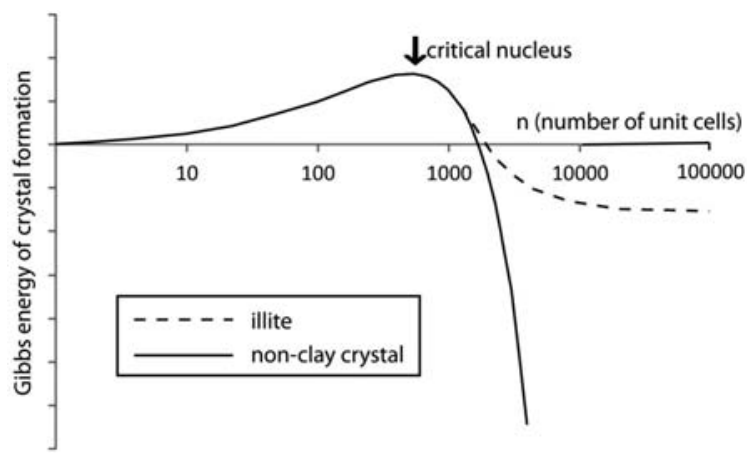

FIG. 1. Gibbs energy of formation for crystal nucleation. The solid curve is for 'normal' minerals that can, potentially, grow to macroscopic sizes. For illite the Gibbs energy is proposed to become asymptotic to some limiting value (dashed curve), so preventing the growth of large crystals, in this case $>\sim 100,000$ unit cells in size. This is due to the strain in the illite lattice, which increases as the crystal enlarges.

\section{Nucleation}

The classical (heterogeneous) nucleation theory of crystals has been described many times, e.g. Lasaga (1998). A cluster of ions (an embryo) that forms in a supersaturated solution is thermodynamically unstable with respect to the solution up to a critical size, known as the critical nucleus (Fig. 1, solid line). Above this critical nucleus size, the incipient crystal will grow spontaneously due to a progressive reduction in free energy with increasing crystal size, in a process that is referred to here as crystal enlargement. The importance of nucleation of clay minerals, when compared to other common authigenic cements such as quartz, can be illustrated by considering the number of times that a crystal must nucleate to form cements in typical abundances. Consider a $1 \mathrm{~cm}^{3}$ block of sandstone, in which $1 \%$ of cement will form. There are $\sim 100-10^{6}$ quartz grains, so that an overgrowth would 'nucleate' a maximum of $10^{6}$ times if an overgrowth were to form on each grain. In contrast, in $1 \mathrm{~cm}^{3}$ of sandstone, $1 \%$ of kaolinite with a crystal diameter of $10 \mu \mathrm{m}$ and length of $1-10 \mu \mathrm{m}$ has $10^{7}-10^{8}$ crystals. For illite, using fundamental particle dimensions reported by Wilkinson et al. (2014), 1\% of illite would comprise $\sim 3 \pm 2 \times 10^{13}$ fundamental particles (1 standard error). The number of crystals (or fundamental particles) of clay minerals, within a given volume of rock is very large compared to other common authigenic cements, from which it is deduced that crystal nucleation will be a stronger control on mineral growth for clay minerals than for other authigenic cements. The generic control on the crystal size of clay minerals is not known, though for illite it is proposed to be due to the strain energy inherent in the stacking of the 2:1 layers
(Radoslovich, 1959). This can be interpreted in terms of the Gibbs energy of formation of the crystals becoming asymptotic to some limiting value (Fig. 1, dashed line).

\section{Implications for the rates of diagenetic reactions}

Many computer models of diagenesis (which are largely calibrated to experimentally determined reaction rates) attempt to correct for the degree of disequilibrium and, typically, use a linear relationship between growth rate and supersaturation (e.g. Gaus et al., 2005; Lander \& Bonnell, 2010; Klein et al., 2013). While this has a sound theoretical basis if the rate-limiting step in crystal growth is crystal enlargement, it may not be correct if the rate-limiting step is crystal nucleation, illustrated here for illite. Equation 1, derived from Wilkinson \& Haszeldine (2002), following Nielson (1964) in Lasaga (1998), shows that for heterogeneous nucleation of a single, $10 \AA$ thick illite layer, the rate of nucleation has a very strong dependence upon supersaturation.

$$
I=\mathrm{C} \exp \left(-\Delta G^{*} \mathrm{~N}_{\mathrm{a}} / \mathrm{R} T\right)
$$

and $\Delta G^{*}=3 \mathrm{~N}_{\mathrm{a}}\left[\sigma_{\mathrm{xxx}} c(a+b)\right]^{2} / \mathrm{R} T(\ln \Omega)$

Where $I=$ rate of nucleation per unit area; $\mathrm{C}$ is a constant; $\mathrm{N}_{\mathrm{a}}$ is the Avagadro number; $\mathrm{R}$ is the gas constant; $T$ is the temperature in Kelvin; $\Delta G^{*}$ is the activation of nucleation; $\sigma_{\mathrm{xxx}}$ is the free energy of the xxx fluid-crystal interface; $a, b$ and $c$ are the dimensions of the unit cell and $\Omega$ is the supersaturation of the pore-fluid.

Using the same approach, it can be shown that a hemispherical nucleus on a planar precursor surface 
has a lower activation energy, so is presumably more likely to form, when:

$$
\left.\Delta G^{*}=\mathrm{N}_{\mathrm{a}}^{2} \pi / 3(a \cdot b \cdot c)^{2}\left(2 \sigma_{100}-\sigma_{001}\right)^{3} / \mathrm{R} T \ln (\Omega)\right)^{2}
$$

To illustrate the difference between the control of growth rate by nucleation and enlargement, the nucleation model described above is contrasted with that of Lander \& Bonnell (2010). The latter uses a nucleation rate equation that assumes that nucleation is fundamentally similar to growth (i.e. the rate is proportional to pore-fluid supersaturation, equation 3) and is chosen here so that both predicted rate curves could be plotted together (Fig. 2). Other authors have used the same rate-supersaturation relationship to describe the rate of crystal enlargement (Gaus et al., 2005; Klein et al., 2013).

$$
I=\mathrm{A} \exp \left(-\Delta \mathrm{G}^{*} / \mathrm{R} T\right)(\Omega-1)
$$

where $I$ is the rate of formation of crystal nuclei per unit area; $\Delta G^{*}$ is the activation energy for nucleation, assumed to be a constant $(73 \mathrm{~kJ} / \mathrm{mol})$ and $\mathrm{A}$ is the so-called pre-exponential constant $\left(8000\right.$ sites $/ \mathrm{cm}^{2} /$ Ma; Lander \& Bonnell, 2010). Figure 2 shows the contrast between the predicted nucleation rates for the hemispherical nucleus and the growth-inspired model of Lander \& Bonnell (2010) - the dependence upon pore-fluid supersaturation is fundamentally different. As a consequence, if an experimentally determined reaction rate, obtained at far-from-equilibrium conditions, is corrected to near-equilibrium conditions for application to the subsurface, then the choice of saturation-rate model will be crucial.

Other suggested reasons for the discrepancy between experimental and real-world reaction rates from the literature can be re-interpreted in terms of crystal nucleation. For in situ rocks the reactive area may be only a small proportion $(<1 \%)$ of the total mineral surface area due to, amongst others, adsorbed organic or other compounds (Pačes, 1983; White \& Peterson, 1990; Maher et al., 2006) or thin mineral precipitates such as chlorite and micro-quartz which are effective barriers to the formation of diagenetic quartz overgrowths (Heald \& Larese, 1974). Surface coordination, in terms of the adsorption and desorption of $\mathrm{H}^{+}$and

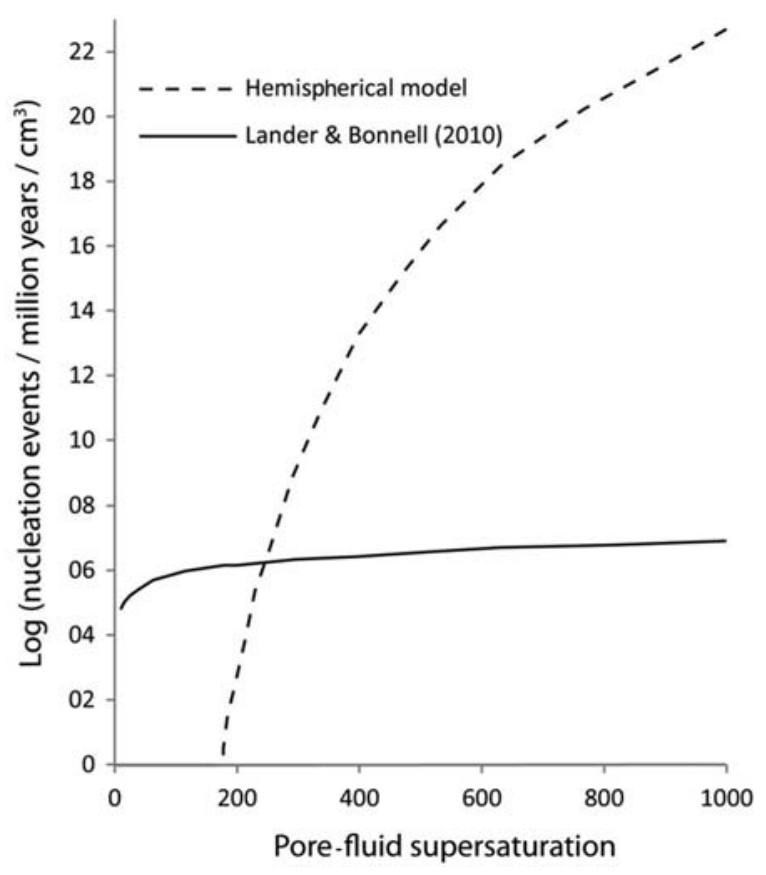

FIG. 2. The dependence of the rate of nucleation of illite upon pore-fluid supersaturation is very different for models based on nucleation theory (hemispherical model) and models based on a crystal-growth equation (Lander \& Bonnell, 2010). The deviation from far-from-equilibrium experiments to near-to-equilibrium natural systems is therefore very dependent on the model used. 
$\mathrm{OH}^{-}$, may not be reproduced adequately in the laboratory but has been shown experimentally to be related to the rate of dissolution (e.g. Brady \& Walther, 1989). In experiments the sample preparation will have generated fresh surfaces that are free from absorbed chemicals and may have high strain energy with surface features such as kinks, ledges and small-area terraces, unless these were removed by sample pre-treatment (Pačes, 1983). Even if an experimental rock sample is prepared with minimal interference, it will have been cored or sawn to shape and in extreme cases, the rock will have been crushed. Regardless of the preparation procedure, the reactive surface area (per unit volume) of rock samples in experiments will exceed that of the insitu conditions, potentially, by orders of magnitude. Consequently, the rate of heterogeneous nucleation, which is proportional to the available surface area, will probably be enhanced substantially in experiments compared to in situ conditions.

Pore-fluid flow rates, which are usually higher for experiments than for in-situ rocks, may also control nucleation as described by Mullin (2001). Hence, experiments with high (laboratory timescale) porefluid flow rates may have more rapid nucleation rates than deeply buried rocks where pore-fluid flow is very slow (mm/year). Finally, the assumption that dissolution rates can be used as a proxy for precipitation rates also fails to capture the importance of crystal nucleation. Dissolution has no nucleation step (unless the formation of etch pits is an exception, though Lasaga \& Luttge (2001) suggested that these form on lattice defects), so, while the rate of dissolution may be an adequate proxy for the rate of crystal enlargement, the experimentally determined dissolution rate of a mineral has no bearing on the rate of growth of a mineral where the rate-limiting step is crystal nucleation. In addition, Arvidson \& Luttge (2010) showed that the non-steady-state dissolution rate of a crystal surface "reflects reactivity inherited from earlier episodes of undersaturation" - i.e. the history of the mineral surface. The same may be true of a surface from a nucleation perspective.

The nucleation control of clay growth may explain a long-standing puzzle from the North Sea - the lack of zero-age illite. Glasmann et al. (1992) observed that the youngest recorded $\mathrm{K}-\mathrm{Ar}$ ages are in the range of 17-25 Ma despite the fact that the basin is currently at its maximum burial depth and, most likely, its maximum temperature. It has been proposed that illite formation was more-or-less continuous during deep burial, but that illite separated for dating is a mixture of recent (zero-age) and older crystals, and that young illite is largely formed as overgrowths on older illite cores (e.g. Hamilton et al., 1989). Here, it is proposed that illite nucleation can only occur during events such as rapid fluid flow, perhaps associated with fault movement, or hydrocarbon charging (Wilkinson \& Haszeldine, 2002). The tectonically quiescent, thermally subsiding North Sea may have simply lacked the crucial fluid flow events to trigger nucleation during the last $20 \mathrm{Ma}$ or so. Equally, a large proportion of the source rocks are very mature or post-mature, so that active charging of traps with hydrocarbons may not be occurring within the depth range of current hydrocarbon exploration. It is proposed that illite nucleation was more common ca. 20-60 Ma ago when the Kimmeridge Clay source rock was at peak maturity, leading to hydrocarbon migration and, hence, hydrocarbon charging of fields.

\section{Reaction rates in carbon capture and storage}

The rates of mineral reactions have implications for industry as they are used within computer models to predict the extent of reaction between artificially injected $\mathrm{CO}_{2}$ and the fluid/host-rock system in geological carbon storage, as a part of Carbon Capture and Storage (CCS). The ability to predict both the short-term (10's years) and the long-term (in this case only 1000 's years) fate of the $\mathrm{CO}_{2}$ confidently may determine whether regulators allow the storage of anthropogenic $\mathrm{CO}_{2}$ in sedimentary basins, or potentially reject the technology as too uncertain. Published examples of computer models of $\mathrm{CO}_{2}$ injection during $\mathrm{CCS}$ often suggest that a high proportion of the $\mathrm{CO}_{2}$ will react with the rock and form stable carbonate minerals (see Wilkinson et al., 2009 for a review). Mineral reaction is desirable from the perspective of the institution that is injecting the $\mathrm{CO}_{2}$, as the solid carbonate minerals are effectively immobile and, as such, cannot escape into the atmosphere and contribute to climate change. However, studies of natural analogues of $\mathrm{CO}_{2}$ storage suggest that, even after geological periods of time, only a relatively small proportion of the $\mathrm{CO}_{2}$ will have reacted to form solid minerals (e.g. Wilkinson et al., 2009; Lu et al., 2011). This leaves a large proportion as a free phase, which could, at least in theory, escape from the reservoir and eventually enter the atmosphere. It should be noted that many natural geological accumulations of $\mathrm{CO}_{2}$ have persisted for millions of years and that these give a high confidence in the security of engineered storage sites.

The Miller oil field in the UK sector of the North Sea is an example of long-term storage of $\mathrm{CO}_{2}$ in a natural 
system. Oil within the reservoir sandstone, at $\sim 4000 \mathrm{~m}$ depth has $28 \mathrm{~mol} . \% \mathrm{CO}_{2}$ in the gas phase (Baines \& Worden 2004). After $\sim 70-80 \mathrm{Ma}$ of residence time only an estimated $6-24 \%$ of the total $\mathrm{CO}_{2}$ is sequestered as calcite, the remainder is dissolved in the oil and in the aqueous pore-fluids (Lu et al., 2011). Within the overlying seal, the $\mathrm{CO}_{2}$ has apparently only penetrated $\sim 12 \mathrm{~m}$, again after 70 $80 \mathrm{Ma}$ of exposure (Lu et al., 2009). These slow rates of reaction are in contrast to those determined by numerical modelling.

Which silicate minerals are involved in $\mathrm{CO}_{2}$ reactions? Distinguishing any silicate mineral reactions from 'ordinary' burial diagenetic reactions within the Miller reservoir using conventional petrographic techniques is virtually impossible. However, using pore-water analyses, Hutcheon et al. (1993) showed that the following reactions apparently controlled water composition and $\mathrm{pH}$ : albite to smectite in basaltic geothermal reservoirs in Iceland; kaolinite to smectite (as interlayers in illite-smectite) in the Patani Basin (Gulf of Thailand) and the USA Gulf Coast. CoudrainRibstein et al. (1998) suggested that six 'elementary' reactions between calcite, clay minerals (kaolinite, chlorite, illite) and other alumina-silicate minerals control the fugacity of $\mathrm{CO}_{2}$ within sediments. Smith \& Ehrenberg (1989) suggested that $\mathrm{CO}_{2}$ was controlled in both the USA Gulf coast and the North Sea by reactions involving feldspar, carbonate and clay minerals, again kaolinite, chlorite and illite. Hence, it seems likely that many of the reactions that will occur as a consequence of injecting $\mathrm{CO}_{2}$ into clastic sedimentary rocks will involve the precipitation of clay minerals. However, without the hydrolysis of silicate minerals to supply cations, then the precipitation of carbonate minerals will be extremely limited and unless the $\mathrm{pH}$ of pore-waters is buffered by silicate mineral reactions, then the injection of $\mathrm{CO}_{2}$ into a sandstone will acidify the pore-waters and cause the net dissolution of carbonate minerals, not their precipitation. If the rate-limiting step of these reactions is the precipitation of clay minerals, then computer simulations that do not include this step, or that model it using inappropriate rates, will not correctly predict the fate of the injected $\mathrm{CO}_{2}$. If the nucleation of clay minerals is a process that requires unusual conditions, and if these conditions are not met during injection, then the socalled sequestration reactions will not occur and the undissolved $\mathrm{CO}_{2}$ will remain as a free phase within the pore space. This is not inherently a problem for Geological Carbon Storage, as storage sites should have adequate structural trapping to ensure that leakage does not occur even if absolutely no long-term reaction takes place between the $\mathrm{CO}_{2}$ and the rock.

\section{CONCLUSIONS AND IMPLICATIONS}

While experiments provide valuable (and indeed indispensable) data to many branches of the Earth Sciences, experimentally determined rates of mineral reactions often cannot be reconciled easily with the rates of geological reactions estimated from natural systems. It is argued here that for the diagenesis of sandstones, an explanation lies with the nucleation kinetics of clay minerals, which may be the ratelimiting step in some diagenetic reactions.

During diagenesis, the rate of dissolution of sparingly soluble detrital minerals such as feldspars may be controlled by the rate of clay-mineral nucleation - if clay minerals cannot precipitate under typical subsurface conditions, then the feldspars will not dissolve as the pore-fluids will hold very little solute. Existing clay mineral crystals cannot simply continue to enlarge as maximum crystal sizes are limited, so that continued precipitation requires nucleation of many new crystals. Hence the dissolution of detrital minerals requires the nucleation of clay minerals.

The nucleation control of clay growth may explain the lack of zero-age illite in the North Sea. Tectonic quiescence and post-mature source rocks may not generate the crucial fluid flow events such as hydrocarbon charging that might otherwise have triggered nucleation during the last $\sim 20 \mathrm{Ma}$.

Numerical models of diagenesis, including those of carbon capture and storage, should include a nucleation stage for clay cements. The very rapid rates of mineralization predicted by many models, when compared to natural analogues, may be a consequence of omitting this rate-limiting process.

\section{ACKNOWLEDGEMENTS}

Some of the ideas in this paper date from the author's $\mathrm{PhD}$, ably supervised by Prof. J.D. Hudson. Others result from long-term collaboration with Profs. R.S. Haszeldine and A.E. Fallick. To John, Stuart and Tony: sincere thanks. The Clay Minerals Group of the Mineralogical Society of Great Britain \& Ireland is also gratefully acknowledged for the invitation to speak at the Mid-European Clay Conference in Dresden, September 2014; for generous financial support for the meeting and for providing the catalyst to revisit the problems discussed here. The paper was improved significantly by reviews by Reinhard Gaupp, Pieter Bertier and Helge Stanjek. 


\section{REFERENCES}

Arvidson R.S. \& Luttge A. (2010) Mineral dissolution kinetics as a function of distance from equilibrium New experimental results. Chemical Geology, 269, 79-88.

Baines S.J. \& Worden R.H. (2004) The long-term fate of $\mathrm{CO}_{2}$ in the subsurface: natural analogues for $\mathrm{CO}_{2}$ storage. Pp. 59-85 in: Geological Storage of Carbon Dioxide (S.J. Baines \& R.H. Worden, editors). Special Publication, 233. Geological Society of London.

Bjørlykke K. \& Aagaard P. (1992) Clay Minerals in North Sea sandstones. Pp. 65-80 in: Origin, Diagenesis, and Petrophysics of Clay Minerals in Sandstones (D.W. Houseknecht \& E.D. Pittman, editors). Special Publication 47 of the Society of Economic Paleontologists and Mineralogists, Tulsa, Oklahoma, USA.

Blum A.E. \& Stillings L.L. (1995) Feldspar dissolution kinetics. Pp. 291-351 in: Chemical Weathering Rates of Silicate Minerals. (A.F. White \& S.L. Brantley, editors). Reviews in Mineralogy, 31, Mineralogical Society of America, Washington, D.C.

Brady P.V. \& Walther J.V. (1989) Controls on silicate dissolution rates in neutral and basic $\mathrm{pH}$ solutions at $25^{\circ} \mathrm{C}$. Geochimica et Cosmochimica Acta, 53, 2823-2830.

Coudrain-Ribstein A., Gouze P. \& de Marsily G. (1998) Temperature-carbon dioxide partial pressure trends in confined aquifers. Chemical Geology, 145, 73-89.

Gaus I., Azaroual M. \& Czernichowski-Lauriol I. (2005) Reactive transport modelling of the impact of $\mathrm{CO}_{2}$ injection on the clayey cap rock at Sleipner (North Sea). Chemical Geology, 217, 319-337.

Glasmann J.R., Clark R.A., Larter S., Briedis N.A. \& Lundeguard P.D. (1989) Diagenesis and hydrocarbon accumulation, Brent Sandstone (Jurassic), Bergen High area, North Sea. American Association of Petroleum Geologists Bulletin, 73, 1341-1360.

Hamilton P.J., Kelly S. \& Fallick A.E. (1989) K-Ar dating of illite in hydrocarbon reservoirs. Clay Minerals, 24, 215-231.

Heald M.T. \& Larese R.E. (1974) Influence of Coatings on Quartz Cementation. Journal of Sedimentary Petrology, 44, 1269-1274.

Hutcheon I., Shevalier M. \& Abercrombie H.J. (1993) pH buffering by metastable mineral-fluid equilibria and evolution of carbon dioxide fugacity during burial diagenesis. Geochimica et Cosmochimica Acta, 57, 1017-1027.

Klein E., De Lucia M., Kempka T. \& Kühn M. (2013) Evaluation of long-term mineral trapping at the Ketzin pilot site for $\mathrm{CO}_{2}$ storage: an integrative approach using geochemical modelling and reservoir simulation. International Journal of Greenhouse Gas Control, 19, 720-730.
Lander R.H. \& Bonnell L.M. (2010) A model for fibrous illite nucleation and growth in sandstones. American Association of Petroleum Geologists Bulletin, 94, 1161-1187.

Lasaga A.C. (1998) Kinetic Theory in the Earth Sciences, pp. 497-551. Princeton University Press, New Jersey, USA.

Lasaga A.C. \& Luttge A. (2001) Variation of crystal dissolution rate based on a dissolution stepwave model. Science, 291, 2400-2404.

Lu J., Wilkinson M., Haszeldine R.S. \& Boyce A.J. (2011) Carbonate cements in Miller field of the UK North Sea: a natural analog for mineral trapping in $\mathrm{CO}_{2}$ geological storage. Environmental Earth Sciences, 62, 507-517.

Lu J., Wilkinson M., Haszeldine R.S. \& Fallick A.E. (2009) Long-term performance of a mudrock seal in natural $\mathrm{CO}_{2}$ storage. Geology, 37, 35-38.

Maher K., Steefel C.I., DePaolo D.I. \& Viani B.E. (2006) The mineral dissolution rate conundrum: Insights from reactive transport modelling of $U$ isotopes and pore fluid chemistry in marine sediments. Geochimica et Cosmochimica Acta, 70, 337-363.

Mullin J.W. (2001) Crystallisation. Elsevier ButterworthHeinemann, Oxford, England.

Nielsen A.E. (1964) Kinetics of Precipitation. Pergamon Press, Oxford, UK.

Pačes T. (1983) Rate constants of dissolution derived from the measurements of mass balance in hydrological catchments. Geochimica et Cosmochimica Acta, 47, 1855-1863.

Radoslovich E.W. (1959) Structural control of polymorphism in micas. Nature, 183, 253.

Small J.S. (1993) Experimental determination of the rates of precipitation of authigenic illite and kaoliniteite in the presence of aqueous oxalate and comparison to the $\mathrm{K} / \mathrm{Ar}$ ages of authigenic illite in reservoir sandstones. Clays and Clay Minerals, 41, 191-208.

Smith J.T. \& Ehrenberg S.N. (1989) Correlation of carbon dioxide abundance with temperature in clastic hydrocarbon reservoirs: relationship to inorganic chemical equilibrium. Marine and Petroleum Geology, 6, 129-135.

Wilkinson M. \& Haszeldine R.S. (2002) Problems with argon: $\mathrm{K}-\mathrm{Ar}$ ages in Gulf Coast shales. Chemical Geology, 191, 277-283.

Wilkinson M., Haszeldine R.S. \& Fallick A.E. (2014) Authigenic illite within northern and central North Sea oilfield sandstones: evidence for post-growth alteration. Clay Minerals, 49, 229-246.

Wilkinson M., Haszeldine R.S., Fallick A.E., Odling N., Stoker S. \& Gatliff R. (2009) $\mathrm{CO}_{2}-$ mineral reaction in a natural analogue for $\mathrm{CO}_{2}$ storage: implications for modelling. Journal of Sedimentary Research, 79, 486-494.

White A.F. \& Brantley S.L (2003) The effect of time on the weathering of silicate minerals: why do weathering 
rates differ in the laboratory and field? Chemical Geology, 202, 479-506.

White A.F. \& Peterson M.L. (1990) Role of the reactive surface area characterisation in geochemical kinetic models. Pp. 461-475 in: Chemical Modelling of Aqueous Systems II (D.C. Melchior \& R.L. Bassett, editors). American Chemical Society, Washington, D.C. 